\title{
A poesia no romance de Mia Couto
}

\author{
Wagner Coriolano de Abreu*
}

\begin{abstract}
Resumo
A fim de palmilhar o romance de Mia Couto, evitando tanto o padrão estético do colonialismo quanto a eliminação das diferenças, tomo como ponto de partida duas hipóteses de Sérgio Farina, quais sejam: a) o texto literário nos leva além de si mesmo; b) para tanto, seu estatuto poético recomenda uma leitura que considere a ambiência histórico-cultural, as múltiplas leituras da estrutura de superfície e a busca da unidade e da estrutura profunda do romance. Assim, Farina afirma que interpretar a obra literária significa trocar experiências culturais e fazer a fusão de horizontes. Com Venenos de Deus, remédios do Diabo - as incuráveis vidas de Vila Cacimba, o escritor Mia Couto volta ao tema das identidades, falando sobre a mestiçagem de culturas, numa história de encontros e desencontros, que se passa em localidade africana, embora pudesse acontecer em qualquer parte do mundo.
\end{abstract}

\section{Palavras-chave}

Poesia. Mia Couto. Venenos de Deus, remédios do Diabo.

Começo com uma afirmação de Mia Couto, inscrita na contracapa do livro de contos do conterrâneo Nélson Saúte: "A literatura moçambicana vive como se fosse o outro nome de Moçambique. O país, em estado de ficção, encontra no escritor um parceiro cúmplice de sua própria invenção" (2007). Mia Couto coloca, lado a lado, a força da ancestralidade com o projeto de escrita representado pelos escritores de antes e de depois da independência.

A literatura moçambicana de que fala o escritor africano se refere aos escritores que ousaram produzir a partir da língua européia. De acordo com o crítico nigeriano Tidjani Serpos, o escritor não está fora da língua, mas está dentro, trabalhando e incorporando termos, expressões e estruturas morfossintáticas de línguas nacionais, de modo que a língua européia, com estes novos ventos, ganha contornos de língua africana e se dobra frente às exigências do pensamento local (PADILHA, 2002, p. 42).

O leitor que atravessa o pórtico de Venenos de Deus, remédios do Diabo ${ }^{1}$ se depara com a transcrição do poema "Imaginação", de um verso só, do poeta brasileiro

* Docente da Faculdade de Tecnologia TECBrasil (FTEC), Brasil. Doutor em Letras pela Pontifícia Universidade Católica do Rio Grande do Sul.

1 COUTO, Mia. Venenos de Deus, remédios do Diabo - as incuráveis vidas de Vila Cacimba. Alfradige: Caminho, 2008. As citações que aparecem são retiradas dessa edição e indicadas pelo número da página onde se encontram, entre parênteses, no corpo do texto, ou dele destacadas. 
Mário Quintana, "A imaginação é a memória que enlouqueceu", bem colocado como anúncio do que encontrará ao longo de cenários e imagens do romance. Com Venenos de Deus, remédios do Diabo - as incuráveis vidas de Vila Cacimba, ${ }^{2}$ o escritor Mia Couto volta ao tema das identidades, falando sobre a mestiçagem de culturas, numa história de encontros e desencontros, que se passa em localidade africana, embora pudesse acontecer em qualquer parte do mundo, conforme afirma ao Jornal Notícias, de Maputo, em 08 de dezembro de 2008.

Como leitor iniciante nas malhas da textualização africana, pretendo tecer uma prosa feita de elementos oriundos do romance, através dos quais percebo a concepção de "falas-em-diferença", propugnada por Laura Cavalcante Padilha. Segundo a professora, a literatura produzida depois de 75 se opõe aos padrões estéticos do colonialismo, à medida que não se deixa rasurar. Agora os textos escrevem "a nação entressonhada, a partir da construção do enredo da utopia" (PADILHA, 2002, p. 37).

Ainda marcado pelos jogos linguajeiros do romance, retornei às palavras do professor Manoel de Souza e Silva, colocadas como pano de fundo na constituição de um mapa da poesia em Moçambique (SILVA, 1996, p. 13 e segs.). Ao identificar a relação de forças no processo de colonização portuguesa em território africano, o ensaísta destaca que as tentativas de eliminação das diferenças obedecem a um processo obviamente redutor. "Apresenta-se, também, a tentativa de diluição da cultura do dominado na do dominador, espécie de genocídio cultural em que as diferenças - naquilo que não fere os interesses da metrópole e dos colonos - são, como costumeiramente, aplainadas, escamoteadas ou, simplesmente, omitidas" (Idem, p. 21).

A fim de palmilhar o romance de Mia Couto, evitando tanto o padrão estético do colonialismo quanto a eliminação das diferenças, tomo como ponto de partida duas hipóteses que Sérgio Farina trabalha na tese Estatuto poético: "literatura não é só estética, é também cultura" e "o texto literário é, simultaneamente, sistêmico e assistêmico" (FARINA, 1996, p. 65 e 69). Comentando o argumento de Iuri Lotman, segundo o qual "uma das funções fundamentais da cultura é a de se opor ao ataque da entropia" (p. 67), Farina afirma que interpretar a obra literária significa trocar experiências culturais e fazer a fusão de horizontes.

Na proposição de Sérgio Farina, o texto literário nos leva além de si mesmo. Para tanto, seu estatuto poético recomenda uma leitura que considere a ambiência histórico-cultural, as múltiplas leituras da estrutura de superfície e a busca da unidade e da estrutura profunda do romance. O leitor primeiro procura por tudo o que envolve o tempo em que a obra foi escrita; em seguida, realiza o exercício da leitura extensiva através dos códigos de sentido e, por último, apresenta um ensaio de leitura profunda, que visa estabelecer o signo-texto.

O primeiro passo - ambiência histórico-cultural - elenca as circunstâncias periféricas, dados biográficos, época, tendência literária, para situar o exercício de

2 COUTO, Mia. Venenos de Deus, remédios do Diabo - as incuráveis vidas de Vila Cacimba. Alfradige: Caminho, 2008. As citações que aparecem são retiradas dessa edição e indicadas pelo número da página onde se encontram, entre parênteses, no corpo do texto, ou dele destacadas. 
crítica no âmbito da recepção e da conexão com o campo da literatura. De acordo com Farina, "todas as informações úteis e necessárias que pudermos recolher sobre determinado texto serão sempre signos que se encontram em contigüidade com o objeto denotado" (p. 72).

O escritor Mia Couto - António Emílio Leite Couto - nasceu em Beira, Moçambique, em 1955, filho de uma família de imigrantes portugueses. Publicou os primeiros poemas aos 14 anos, no jornal Notícias da Beira. Em 1972, mudou-se para Lourenço Marques a fim de estudar Medicina. A partir de 1974, iniciou curso de Jornalismo e, com a independência de seu país, assumiu a direção da Agência de Informação de Moçambique (AIM). Antes de publicar o livro de estréia "Raiz de Orvalho", em 1983, já havia participado de uma antologia poética, em edição do Instituto Nacional do Livro e do Disco, onde aparece também o poeta moçambicano Orlando Mendes. Nessa época, dedica-se aos contos e às crônicas, que circulam em semanários moçambicanos, em especial, na capital Maputo (nome atual da cidade Lourenço Marques). Em 1985, formou-se em Biologia pela Universidade Eduardo Mondlane e, posteriormente, tornou-se especialista em Ecologia. Além de biólogo e professor, é um grande produtor literário.

$\mathrm{Na}$ formação de Mia Couto, aparecem as marcas de uma prática de leitura que foi forte nos anos 60 e 70, quando o Brasil visitava Moçambique por meio da literatura, da poesia. "Estou muito marcado pela poesia, eu sou um poeta que conta histórias e tive mestres importantes como João Cabral de Melo Neto, como Drummond de Andrade [...], como Manuel Bandeira, como Adélia Prado mais tarde, Manuel de Barros, que são importantes para mim" (OLIVEIRA, 2009). Dos anos 80, com a obra publicada, vem a popularidade dentro e fora do país e, como outros produtores africanos, inicia um caminho inverso ao que foi no passado, quando no presente junto com outros africanos traz ao Brasil a contribuição de valores da cultura local. Na mesma entrevista, o escritor declara: "Tenho todo o prazer em que o meu nome esteja associado ao nome do país, de uma terra que ainda tem que se afirmar, e me orgulho por isso. Mas não estou em lugar cimeiro de nada, olho para mim como um aprendiz que se sente no princípio da sua própria carreira" (Idem).

De contos e crônicas, Mia Couto organiza "Vozes anoitecidas" (1987) e "Cronicando" (1991). O primeiro romance, "Terra sonâmbula" (1992), arrebata o título de "um dos doze melhores livros africanos do século 20". Outras obras publicadas: "Estórias abensonhadas" (1994), "A varanda do Frangipani" (1996), "Contos do nascer da terra" (1997), "Vinte e zinco" (1999), "Raiz de orvalho e outros poemas" (1999), "Mar me quer" (2000), "O último vôo do flamingo" (2000), "Na berma de nenhuma estrada e outros contos" (2001), "O gato e o escuro" (2001), "Um rio chamado tempo, uma casa chamada terra" (2002), "O fio das missangas" (2004), "A chuva pasmada" (2004), "Pensatempos: textos de opinião" (2005), "O outro pé da sereia" (2006), "Idades, cidades, divindades" (2007), "Venenos de Deus, remédios do Diabo" (2008) e "Antes de nascer o mundo" (2009).

Da premiação alcançada, destacam-se o Prêmio Vergílio Ferreira pelo conjunto da obra (1999) e o Prêmio Mário António, atribuído pela Fundação Calouste Gulbenkian a autores e obras dos países africanos lusófonos (2000). Mia Couto escreveu e 
adaptou diversos textos para o teatro, sendo que alguns foram representados pelo grupo moçambicano Mutumbela Gogo. No Brasil, o escritor tem dois registros importantes: sócio correspondente da Academia Brasileira de Letras (1998) e escritor premiado pela Jornada Nacional de Literatura de Passo Fundo, Rio Grande do Sul (2007). O nome "Mia" é proveniente de sua paixão pelos gatos e pelo fato de seu irmão menor, em tempos de infância, não conseguir proferir seu nome corretamente.

A leitura extensiva - $O$ texto e suas múltiplas leituras - "terá que explicar racionalmente a linguagem e o conteúdo artístico" (FARINA, p. 79). O segundo passo, portanto, descreve o texto, em seus elementos externos e internos, e destaca a poeticidade da prosa, através do ritmo e da ambigüidade.

Venenos de Deus, remédios do Diabo compõe-se de dezoito capítulos e um subtítulo, cujo sentido se relaciona à vida das personagens: as incuráveis vidas de Vila Cacimba. A começar pelo título, a linguagem figurada, por meio de uma antítese, antecipa a poeticidade que o leitor encontrará na ideia de cacimba. "A neblina - que deu nome à Vila - é a fuligem das nuvens. E em nenhum outro lugar há tanta nuvem ardendo" (COUTO, p. 32).

A respeito deste romance, Mia Couto diz que "no domínio da linguagem eu faço uma coisa que penso que é nova, como, por exemplo, sou mais comedido na invenção de palavras, fazendo-o só quando era preciso e não como um factor de busca literária ou marca" (COUTO, 08 dez. 2008). E, ainda, acerca do narrador, o escritor registra que "aparece pela primeira vez num livro meu como personagem também; ele entra na história, tem opiniões, dialoga com as outras personagens, o que faz com que a fronteira entre o narrador e os outros intervenientes da história seja sacudida" (Idem).

A história de que fala o escritor se organiza numa rede de cenas no interior da casa dos Sozinhos - Bartolomeu, Munda e Deolinda, e de cenas no âmbito da Vila e alguma saída à cidade, onde circulam Suacelência, Esposinha, os Tresandarilhos e o Mensageiro ${ }^{3}$. A cidade de Lisboa e os mares navegados aparecem, respectivamente, na cena do encontro do médico lusitano com a mulata africana, no capítulo doze, e na cena do mecânico Bartolomeu atravessando mares, como o único negro da tripulação do paquete Infante D. Henrique, da Companhia Colonial de Navegação, no primeiro capítulo.

A descrição interna do romance fornece um esquema das ações principais, que dá conta da narração. Farina denomina esta etapa como processo da compreensão, visto que "o texto começa a revelar-se" (FARINA, p. 83). Os momentos estruturais intrínsecos - início, ação deflagradora, seqüências narrativas, clímax e ação final aparecem quando da síntese do romance.

A história inicia com a visita do médico português Sidônio Rosa ao mecânico Bartolomeu Sozinho, africano de Moçambique, que se encontra recolhido dentro de casa. Os dois conversam sobre sonhos, viagens, casamento e sobre o inimigo

3 Ana Cláudia Coutinho, em resenha do romance, observa que "em traços largos podemos começar por apontar que, nesta obra, Mia Couto abandona o frenesim dos neologismos, limitando-se ao estritamente necessário para que se perceba a sua mestria nesse domínio. Além disso, e ao contrário do que acontece na esmagadora maioria dos seus romances anteriores, Venenos de Deus Remédios do Diabo é uma narrativa que conta com muito poucas personagens e cuja acção se circunscreve a um espaço muito limitado" (COUTINHO, 2008). 
Suacelência. Bartolomeu, quando jovem, se tornou embarcado no transatlântico Infante Dom Henrique, que aportou na costa africana. Munda trabalha no Hospital. A mulher fala das impertinências do marido, que não quer vê-la lavando a roupa dos doentes, com receio da presença dos espíritos. O narrador revela que a mulher é mulata, que teve coragem de casar com um negro, numa localidade onde isso não acontece. Munda mostra a carta que chegou de Deolinda ao médico e pede que a leia. A moça quer que os pais fiquem bem e pretende se casar na presença dos dois.

O administrador Suacelência questiona a razão de tantas visitas a um paciente, enquanto há tantos doentes na Vila. Solicita um remédio que elimine a transpiração corporal. O médico e o mecânico entretecem um diálogo filosófico em torno do cigarro e da condição de poeta de Bartolomeu. Munda e Sidônio conversam sobre álbum de família. Bartolomeu começa a interagir, falando do quarto onde se encontra. Marido e mulher se desentendem.

Sidônio conhece Deolinda, em Lisboa, durante um congresso. A moça mostra-se interessada, mas imagina que ele não a quer. Ele diz que tem medo de não regressar deste envolvimento. O pai do médico vivera na África, à época acreditando poder ficar longe do fascismo. O mecânico pergunta ao médico a razão de sua vinda à África, pois não acredita ter sido apenas por Deolinda.

Bartolomeu sai de casa como cirandarilho. Temendo que algo aconteça, Munda pede ao médico que o procure. É o primeiro encontro do médico lusitano com a realidade do local. "À medida que se afasta dos recantos que ele tão bem conhece, Sidônio vai-se perdendo em labirínticas paisagens. As ruinhas se convertem em tortuosos atalhos, as pessoas deixam de falar português. O médico afunda-se num mundo desconhecido, fora da geografia, longe do idioma" (p. 116). O narrador informa que ele é uma "solitária raça que caminha nos atalhos de uma vila africana" (p. 117).

O médico encontra Bartolomeu dentro de um barracão como se tivesse estado com uma miúda ainda não quente. Sidônio diz que ele deveria estar fazendo amor com a esposa, mas o mecânico insiste que ela não quer e precisa de um remédio para querer. Sidônio pergunta a Munda sobre a vida íntima do casal, as razões pelas quais não se deitavam juntos. Descobre que Barto teve uma história com Deolinda. O narrador afirma que há "uma poeira de dúvida sobre o assunto" (p. 123).

Munda encontra uma foto junto aos pertences do marido. Bartolomeu informa que se trata de Isadora, filha que teve em uma das viagens como embarcado. Isadora ficara aos cuidados da avó, assim que a mãe - affair de um encontro - morrera. Munda não o perdoa por ter tido uma filha com outra mulher. Bartolomeu revela a Sidônio que sabe da mentira a respeito de sua formação de médico. Da pasta que entrega ao médico, caem pelo chão as inúmeras cartas que escrevera para Deolinda, porém nunca foram postadas. Prestes a viajar, o médico é chamado para atender Bartolomeu. Na visita, descobre que Deolinda fora violada quando menina. Munda nunca mais se deitou com o marido depois que soube do incestuoso adultério. Revela ao médico que foi amante do inimigo, mas que o administrador também a traiu com Deolinda.

O médico presta os primeiros socorros ao administrador no Posto de Saúde. Dona Esposinha informa que o marido abusou da medicação. Sidônio percebe que 
alguém tentou envenenar o administrador com uma mentira. Conversa com Munda, que conta como foi que aconteceram os fatos envolvendo sua família e o administrador. Deolinda morreu antes de o médico chegar a Vila Cacimba, após ter feito um aborto, tentando tirar um filho de Suacelência. $O$ médico não quer escutar mais nada. $O$ narrador estabelece uma relação entre o sonhar e o viver.

Sentado na escadaria do Posto de Saúde, o médico espera a caminhonete para deixar Vila Cacimba, pensando que "em África aprendi a escutar e não apenas a falar". Pede ao administrador que conte a verdade sobre os fatos da Vila, pois está muito confuso. Suacelência informa que Deolinda estava em fase terminal. Sidônio deixa as malas com Suacelência, vai ao cemitério. Encontra Munda que Ihe oferece umas flores brancas, o beijo-da-mulata. Sidônio cai num sono profundo. Quando acorda, vê uma mensageira que desaparece no nevoeiro. $O$ narrador expõe o adoecimento das casas da Vila.

Venenos de Deus, remédios do Diabo, sob o ponto de vista da estrutura narrativa, apresenta uma organização interna com ritmo alternado dos quadros em movimento. Como estrutura heterogênea, o romance se explica pela ambigüidade como um "salto que o sentido dá para fora da rigidez dos usos comuns e dicionarísticos, revelando estranhas e insólitas intimidades. A ambigüidade é a autoridade homologadora do alto ou baixo nível de poeticidade de qualquer texto" (FARINA, p. 98). Há muitos caminhos que levam à ambigüidade no texto e podem ser reconhecidos por meio de suas marcas ou códigos. Os códigos são pontos de significação onde nossas experiências de pluralidade se confinam no sentido. Das muitas veredas que o leitor encontra no romance de Mia Couto, destaco os códigos lexical, idiomático, estilístico, metaficcional, político, histórico, temporal, espacial, familiar, libidinoso, sensual e simbólico, com os quais elaboro considerações sobre a linguagem, a história e a fiç̧ão na literatura deste escritor.

Escrito em língua portuguesa, o romance reúne marcas da prosa escrita em Portugal, bem como traços da língua assimilada pelos falantes africanos e contaminação de línguas africanas e expressões chinesas. Uma expressão típica do lugar é tchovado, que significa empurrado. Vem do verbo Kutshowa (empurrar, em língua tsonga), faz parte do português moçambicano (p. 85). Barto diz ao médico: Mezengu wa matudzi, porcaria de branco, em língua xi-sena, falada no centro de Moçambique. E em seguida usa uma expressão chinesa, "ini nkabe piva, taiu", que quer dizer "eu não entendo" (p. 93). A variedade lingüística culta aparece com certa regularidade, embora haja emprego de neologismos, como em "artmosfera" (p. 107) e "arrelampado" (p.20). Mia Couto se vale de uma prosa poética, visto que "há a invasão do eu do autor, introduzindo o ponto de vista lírico na narrativa" (HOUAISS, p. 2314).

O código estilístico rende um estudo à parte, tamanha a beleza da linguagem figurada do romance. No que tange à questão do sonho, as personagens manifestam diferentes perspectivas, sonho como vida, como cura, como doença. A mulher diz que sonhar restitui o viver (p. 180), o médico diz que sonhar traz a cura (p. 17) e o mecânico se queixa do sonhar como cansaço da vida (Idem). 
Desde a chegada de Sidônio até sua partida, o tempo transcorre normal na Vila. O que se sobressai é o cotidiano e a luta pela cura das lembranças, que as personagens têm em relação ao passado e às paixões. O lugar onde acontecem as ações não fica bem delimitado. Tudo parece uma nuance de um território onde sobrevivem seres que se escondem, fora das ruas, à espera de um navio da partida ou tomados pela presença da autoridade que põe ordem no andar da Vila.

O romance conta uma história no pós 75 de Moçambique. A Vila Cacimba vive um tempo em que os soldados adoecem de meningite e estão tresandarilhos. É um tempo posterior à presença da Companhia Colonial de Navegação. As relações de força do antes e do depois da independência se misturam, revelando os resquícios da ideologia colonial ainda presente nas relações cotidianas. O que ilustra muito bem esta permanência pode ser lido no enfrentamento entre o mecânico e o administrador. A inimizade tem raízes desde o dia em que o navio português encalhou na proximidade da Vila, ficando sem mecânico devido à doença que toma a tripulação. Um velho mecânico conduz seu neto a exercer o ofício, de modo que o jovem se torna mecânico da embarcação, e segue viagem a outros lugares. Outro jovem embarcado não tem a mesma sorte e adoece, tendo que retornar para a Vila. Surge, desde então, uma disputa entre os dois, em constante jogo de mentiras e verdades.

O romance se estrutura num jogo de aparências, entre as quais, temos a história de Deolinda, a mulata que foi criada como filha de Bartolomeu e Munda. A esposa do mecânico não teve filhos. Quando chegam a Vila Cacimba, com a menina, todos pensam que a pequena é filha do casal. De modo paulatino, aparecem outras relações familiares, como na cena do casal e Deolinda, que foi colocada no lugar de filha; na crítica à esposa do administrador, que de tão inexpressiva se torna esposinha, e na ausência de família do médico. É neste âmbito que se torna possível desanuviar os acenos do incesto. Sidônio descobre que Bartolomeu teve uma relação com Deolinda, supostamente filha, o que caracterizaria um incesto. Todavia, ficará sabendo que Deolinda era irmã de Munda, portanto, cunhada do mecânico, dando então um sentido deslocado ou de conotação local ao incesto. O episódio suscita interesse de estudo antropológico das relações parentais em África.

O nevoeiro que cobre a Vila todo tempo, em especial, quando Sidônio sai a procurar Bartolomeu, exemplifica o simbólico no romance. Outro índice pode ser reconhecido no mensageiro que traz as cartas de Deolinda e as entrega a Munda. A poalha que cobre a quase totalidade das relações entre as personagens, inclusive a intervenção do narrador, pode ser tomada como mágica, evocativa, simbólica no contexto cultural. Contamina, inclusive, as relações subjetivas. Sidônio não é formado, mas exerce a profissão de médico na Vila. Bartolomeu confessa ser apaixonado por Munda, mas teve um affair amoroso que gerou Isadora. Munda se reconhece católica fervorosa, mas tem práticas de feiticeira. Suacelência diz que nada teve com Deolinda, mas esteve envolvido sexualmente com ela e a irmã.

Com certeza, a seleção de códigos oferece apenas algumas possibilidades de leitura, sendo que o exercício possibilita o encontro de outras veredas inscritas no tecido do romance. Todavia, observa Farina, "uma boa compreensão do texto não pode ficar na agradável dispersão dos códigos. É necessário que se tente uma síntese 
que apresenta a tensão inoculada nele" (FARINA, 1994, p. 11). Venenos de Deus, remédios do Diabo apresenta sua estrutura de superfície na dicotomia doença e cura. De ponta a ponta no livro, o leitor encontrará uma tessitura de cenas envolvendo a doença com uma perspectiva remota de cura.

O médico português chega a Vila Cacimba, assume o posto de saúde, e empreende visitas à casa da família de Deolinda, a fim de acompanhar o estado de saúde do velho Bartolomeu. O mecânico se encontra com o corpo frágil, com tosse e tonturas, esquecimentos e dores (p. 83 e segs.). Sabendo das visitas, o administrador reclama desta exclusividade ao próprio médico, pois na vila há muitos doentes. 0 administrador pede ao médico um remédio que elimine a doença que se espalhou na Vila, e outro para cessar sua transpiração corporal (p. 67 e segs.). A mulata Deolinda, segundo o narrador e as personagens, teve a saúde abalada, ou por um aborto malsucedido, ou por uma doença terminal, provavelmente a AIDS (p. 171 e segs.).

Com o último passo - a busca da unidade e da estrutura profunda - o estatuto amarra a leitura, por meio da junção entre ambiência histórico-cultural e leitura extensiva, visando alcançar a estrutura profunda do texto. O poeta Otávio Paz afirma que as semelhanças ao lado das diferenças produzem uma terceira via, que ele denomina de identidade (FARINA, 1996, p. 106). Na metodologia do Estatuto poético, o esforço da síntese leva o nome de signo-texto, que tem parentesco direto com a concepção de arquissema, de Lotman, e não é dado diretamente na obra literária, mas numa palavra-chave que enfeixe as diversas oposições semânticas (LOTMAN, 1978, p. 251). A palavra que estabelece uma gama extensa de relações no romance é poesia.

A palavra poesia, além de aparecer literalmente no romance, comparece pela composição criativa de imagens poéticas e jogos de figuração. Quanto ao registro da palavra, destaco o diálogo emblemático entre Bartolomeu e Sidônio, no capítulo sete, quando o mecânico analisa uma forma de expressão usada pelo médico, desvelando o seu sentido metafórico: "- Acha que isso é poesia?/- Então não é? Cortar-se na bebida? A gente pode cortar nas árvores, cortar na roupa, cortar sei lá onde, mas diga lá, Doutor, que faca corta um líquido? Só a faca da poesia" (COUTO, p. 64). Quanto ao jogo poético, destaco o diálogo entre Suacelência e Sidônio, no capítulo oito, quando o administrador compara o médico recém-chegado ao padre da Vila: "Você é diferente do padre daqui da Vila./- E por quê?/- Os padres, eu conheci-os muito bem, tratam a alma como uma árvore: podam-na. O senhor, não. O senhor trata, digamos, do corpo espiritual" (Idem, p. 73).

A considerar o signo-texto como centro do mistério inteligível do texto, como faz o estatuto poético de Farina (1996, p. 111), tomo a poesia como "a arte de excitar a alma com uma visão do mundo" (HOUAISS, p. 2246), e também como texto poético de caráter subjetivo, em que o poeta expressa seu mundo interior (Idem). Segundo estas acepções, como leitor da poesia que há no romance de Mia Couto, encontro imagens primitivas que revelam elementos profundos ligados aos primórdios da civilização africana: a mulher afirma que na África há familiares que entregam as cartas, os misteriosos mensageiros (p. 47) e teme que Bartolomeu a difame na Vila como feiticeira, e com isso seja condenada (p. 58). Estas cenas colocam modos 
peculiares que o agrupamento africano inventou, quando da ocupação daquele lugar, que por certo se desvelam ao contato com o sistema local da cultura.

O contraponto entre poesia e história oferece outras imersões nas atitudes primitivas retratadas no signo-texto de Venenos de Deus, remédios do Diabo. A cena do capítulo 12, onde o médico e o mecânico iniciam uma prosa sobre identidade, revela a força do processo colonizador, quando Bartolomeu muda de nome, "se colonizara a si mesmo" (p. 110), por vergonha de seu nome original, e não acreditar que um mecânico pudesse se chamar Tsotsi, como fora batizado; a cena do capítulo 15, em que o mecânico diz que o médico pode ser tomado por traficante de órgãos, como acontecera a outro português, pois é o que os africanos têm a oferecer. "Sidónio está pálido, sobre ele recaem os mitos de um continente pleno de imprevisíveis perigos" (p. 143). E, por último, a cena do capítulo 18, na qual o narrador fala do tratamento que Suacelência deu a Deolinda, quando estava em fase terminal da doença. Foram a um curandeiro no Zimbábue, mas ela não melhorou. Após o regresso, veio a ser enterrada no cemitério dos alemães, indigente e quase sem corpo (p. 174).

Tanto na citação dos familiares da África como na citação da história que alimenta a poesia, encontro um sentido para a expressão "falas-em-diferença", aquela que indica a possibilidade de que "o ocidente veja a África com olhos africanos e não ocidentais" (TUTIKIAN, p. 24). A interface que estabeleci com a proposta de encarar o romance pelo mundo-eixo - como também se pode referir ao signo da unidade textual - teve como horizonte a busca pela leitura profunda e criteriosa, de uma produção que aos poucos começo a perceber na nuance e profundidade. $O$ ato de leitura do produto literário africano, a meu ver, pode problematizar a falta de uma formação em estudos africanos, nos termos em que Laura Padilha vem discutindo a questão.

\section{Referências}

COUTINHO, Ana Cláudia. Mia Couto, Venenos de Deus, Remédios do Diabo - As incuráveis vidas de Vila Cacimba. www.revistaautor.com/index2.php?option= com_content\&do_pdf=1\&id=352. Capturado em 24 de fevereiro de 2011.

COUTO, Mia. A fronteira da cultura. Continente Multicultural, Recife, Ano III, n. 34, p. 52-56, outubro de 2003.

COUTO, Mia. Contracapa. In: SAÚTE, Nelson. Rio dos bons sinais. Rio de Janeiro: Língua Geral, 2007.

COUTO, Mia. Venenos de Deus, remédios do Diabo: as incuráveis vidas de Vila Cacimba. Alfragide: Caminho, 2008.

COUTO, Mia. Entrevista a Gil Felipe. Jornal Notícias, Maputo/Moçambique, $08 \mathrm{dez}$. 2008.

FARINA, Sérgio. Quando o texto é um poema. Agenda de linguagem Palavra Comovida, São Leopoldo, Unisinos, 3 (17): 10-11, mar. 1994

FARINA, Sérgio. Estatuto poético: uma proposta metodológica de leitura analítica e interpretativa. São Leopoldo: Editora UNISINOS, 1996. 
HOUAISS, Antônio. Dicionário Houaiss da língua portuguesa. Rio de Janeiro: Objetiva, 2001.

LOTMAN, Iuri. A estrutura do texto artístico. Lisboa: Editorial Estampa, 1978.

MATAMBANADZO, Isabella. Mulheres do Zimbábue em ação contra a AIDS. Tradução Amanda Presotti. Labrys, études féministes/estudos feministas, França/Brasil, janeiro/julho de 2004.

OLIVEIRA, Conceição (Notas). Mia Couto fala sobre África, Moçambique, Beira e Literatura. Programa Nova África (TV Brasil/EBC S.A.), Rio de Janeiro, junho de 2009. http://tvbrasil.ebc.com.br/novaafrica/tag/mocambique. Capturado 25 de fevereiro de 2011.

PADILHA, Laura Cavalcante. Novos pactos, outras ficções: ensaios sobre literaturas afro-luso-brasileiras. (Coleção Memória das Letras, 10). Porto Alegre: EDIPUCRS, 2002.

QUINTANA, Mário. Caderno H. (Coleção Sagitário). 4 ed. Porto Alegre: Globo, 1983. SOUZA E SILVA, Manoel de. Do alheio ao próprio: a poesia em Moçambique. São Paulo: Edusp; Goiânia: Editora da UFG, 1996.

TUTIKIAN, Jane. Velhas identidades novas: o pós-colonialismo e a emergência das nações de língua portuguesa. Porto Alegre: Sagra Luzzatto, 2006.

\section{Title}

Poetry in Mia Couto's Novel.

\section{Abstract}

In order to map Mia Couto's novel, while avoiding both the colonialist aesthetic pattern and the elimination of differences, I take as my parting point two hypotheses by Sérgio Farina, that is, (1) the literary text takes one beyond him/herself. (2) For such, its poetic statute recommends a reading, which takes into consideration the historical-cultural environment, the multiple readings of the surface structure and the search for unity by the novel's deep structure. Thus, Farina claims that to interpret a literary work means to exchange cultural experiences and to make a fusion of horizons. With Com Venenos de Deus, remédios do Diabo - as incuráveis vidas de Vila Cacimba, the writer Mia Couto returns to the theme of identities, speaking of the blending of cultures, in a story of encounters and flights, which takes place in an African site, tough it could happen anywhere in the world.

\section{Keywords}

Poetry. Mia Couto. Venenos de Deus, remédios do Diabo.

Recebido em 06.09.2011. Aprovado em 29.11.2011. 